\title{
Numerical calculation of bridge seismic response considering beam-block collision effect
}

Cálculo numérico de la respuesta sísmica del puente considerando el efecto de colisión haz-bloque

Wang Shuijiang (Main and Corresponding Author)

Sichuan College of Architectural Technology

Deyang, Sichuan, 618000 (China)

429-755369@u.xjournal.net

Manuscript Code: 1101

Date of Acceptance/Reception: 05.03.2019/12.04.2018

DOI: $10.7764 /$ RDLC.18.1.111

\begin{abstract}
During earthquake, collision between the beam and the block is the direct factor causing damage to the block. To better study the problem and the variation of seismic response in transverse direction of bridge arising from collision, it is necessary to perform quantitative analysis. The Kelvin contact unit model and the single-step Houbolt (SSH) numerical calculation method are adopted for the problem in order to deduce the numerical calculation method and procedures of the bridge seismic response considering beam-block collision effect. MATLAB is used to prepare corresponding program. Through comparison of the calculation result with the test data in related references, it is seen that the calculation method put forward in the paper is of high calculation efficiency and accurate result. In addition, a specific example is made to validate the practicability of this method.
\end{abstract}

Keywords: seismic response, Kelvin model, block, collision effect.

Resumen

Durante un terremoto, la colisión entre el haz y el bloque es el factor directo que causa daño al bloque. Para estudiar mejor el problema y la variación de la respuesta sísmica en la dirección transversal del puente que surge de la colisión, es necesario realizar un análisis cuantitativo. El modelo de unidad de contacto Kelvin y el método de cálculo numérico Houbolt (SSH) de un solo paso se adoptan para el problema con el fin de deducir el método de cálculo numérico y los procedimientos de la respuesta sísmica del puente considerando el efecto de colisión del bloque del haz. MATLAB se utiliza para preparar el programa correspondiente. A través de la comparación del resultado del cálculo con los datos de la prueba en referencias relacionadas, se ve que el método de cálculo presentado en el documento es de alta eficiencia de cálculo y resultado preciso. Además, se hace un ejemplo específico para validar la viabilidad de este método.

Palabras clave: respuesta sísmica, modelo de Kelvin, bloque, efecto de colisión.

Introduction

The bridge suffers from damage by great earthquake almost every time. The most common damage type for concrete bridges includes the pier bending damage, pier shear damage, beam falling damage, and bearing damage. Falling beam will cause the beam to a complete failure, resulting in great inconvenience to the rescue work, which shall be avoided as much as possible. The transverse anti-shock block is the most widely used transverse falling-off prevention measure, but the study on the collision between the block and the beam and variation caused by seismic response in 
transverse direction of bridge is still insufficient. In the process of earthquake, the collision between beam and block is the direct factor causing block damage. the overall objective of the study is to achieve a better understanding of the lateral seismic response caused by bridge collision through quantitative analysis.

State of the Art

In 2002 and 2007, the University of California, San Diego, published the reports on the stress and damage of abutment retaining blocks as sacrificial members, which reported that the failure modes of baffle block with different design methods based on experimental study (Megally, Silva, \& Seible, 2001; Azadeh, 2007). Maleki (2004) simplified a simply supported girder bridge with the block as a spring-mass model and took the self-vibration period of the bridge, block rigidity, and initial clearance as parameters for analysis. Goel \& Chopra (2008) analyzed the action of bridge block crossing over the seismic belt, studied three cases: without a block, linear elastic block, and non-linear block. He believed that the existing block changed the load bearing condition. Deflection and load-bearing condition of both the abutment and the pier were different under the condition of with or without the block, so it is unsafe to ignore the role of the block. In domestic seismic design specifications, the block was taken as the structural measure without load-bearing analysis. There were neither defined regulations on the type and size of the block nor deep further study. Wenchuan Earthquake caused damages to large amount of blocks. Li et al. (2008) and Wang et al. (2009), et al made site survey in the disaster area, and obtained valuable materials, providing reference significance for further study on the problem.

There are many numerical methods for dynamic analysis. Although there is not any method to reach all purposes, a competitive method usually has the following attributes (Hilber \& Hughes, 1976): 1) it can indicate unconditional stability when applied to linear problem; 2) the implicit equation of each solution procedure shall be no more than one pair; 3) second order accuracy; 4) there is controllable numerical damping within the high-frequency scope; 5) automatic start-up. The numerical damping is designed to reduce interference and non-physical vibration caused by indistinguishable motivation due to high-frequency space, which is very important to solve the collision problem (Gregory, 1996). Houbolt method (Houbolt, 1950) is a prior method containing numerical damping, which will dissipate not only the high-frequency component but also low-frequency component, and the method requires other procedures for activation. The single-step Houbolt method developed based on Houbolt method can solve the self-starting problem, but different parameters have great effect on the calculation result. Chung \& Hulbert (1994) gives the suggestive values for these parameters based on the gradual dissipation and second order accuracy. SSH method is selected in the paper to deduce the numerical calculation method for the beam-block collision problem.

All in all, in order to present the relevant research of this paper, the Kevin contact element model and the SSH numerical calculation method were used to drive the numerical calculation method and procedure for bridge transverse seismic response with respect to beam-shear key pounding effect. MATLAB language was used to develop the computer program. Furthermore, the practicability of the proposed method was validated through an example.

Methodology

\section{Beam-block collision model}

Kelvin model is composed of one spring unit and one damper unit. The spring is used to represent contact between collision objects, while the damper is used to describe the energy loss in collision. If the spring rigidity $\left(k_{k}\right)$ and damping coefficient $\left(c_{k}\right)$ is known, the following formula is used to calculate the collision force: 


$$
\begin{gathered}
F_{c}=\boldsymbol{k}_{k}\left(\boldsymbol{u}_{1}-u_{2}-g_{p}\right)+c_{k}\left(\dot{u}_{1}-\dot{u}_{2}\right) ; u_{1}-u_{2}-g_{p} \geq 0 \\
0 ; u_{1}-u_{2}-g_{p}<0^{u_{1}-u_{2}-g_{p} \geq 0}
\end{gathered}
$$

(1b)Where, $k_{k}$ is rigidity

parameter, $c_{k}$ is damping coefficient, and $\dot{u}_{1}-\dot{u}_{2}$ is the penetration velocity.

For Kelvin model, negative collision force may occur after the collision due to the damping term, so that the separating colliding objects will collide again. To avoid this kind of the phenomenon, fine adjustment is made to the model. At the time of the collision force changing from positive to negative, both the spring and the damper are removed. It is assumed that both colliding objects are separate, certain plastic deformation will leave in the collision area (Petro et al. 2007). In the case, the calculation equation for collision force is expressed as follows:

$$
F_{c}(t+\Delta t)=C_{k} \dot{u}_{t+\Delta t}+K_{k} u_{t+\Delta t}-k_{k} g_{p} l, \quad F_{c}(t)>0
$$

)

$$
F_{c}(t+\Delta t)=0, \quad F_{c}(t) \leq 0
$$

) After the Kelvin model is improved, the relationship between collision force and relative amount of indentation is changed as shown from Figure 1 (a) to Figure 1 (b), and then the calculation model for the beam-block collision is performed with the contact unit method of Kelvin model, as shown in Figure 2.

Figure 1. Kelvin model contact force-displacement relationship (Source: Petro et al. 2007).
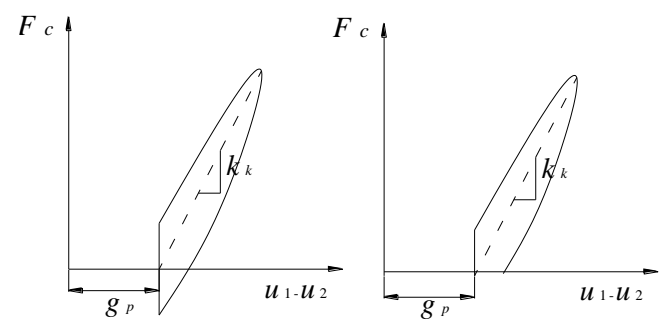

Figure 2. Simplified impact model (Source: Petro et al. 2007).

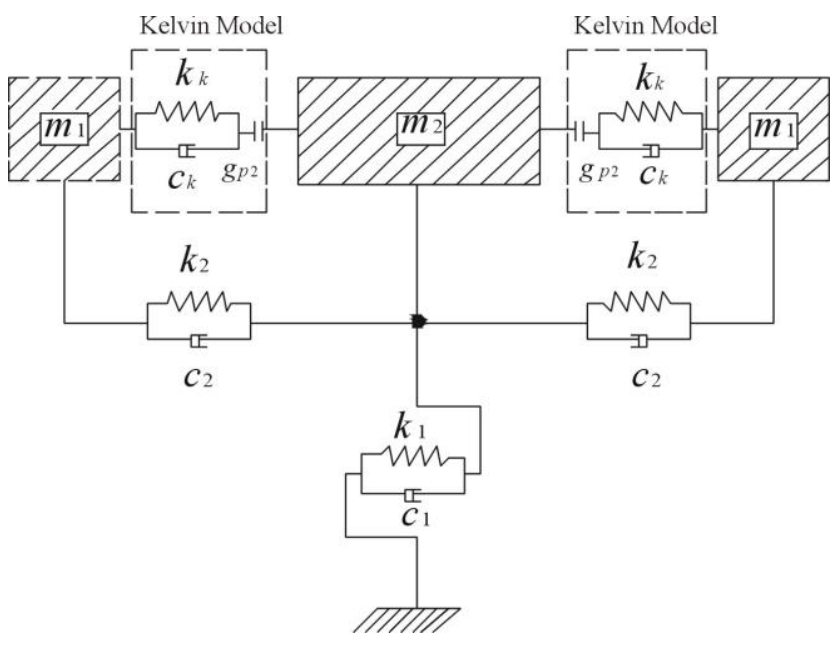




\section{Beam-block numerical algorithm}

The contact dynamic equation considering the beam-block collision is shown below:

$$
\boldsymbol{M} \ddot{u}+\boldsymbol{C} \dot{u}+\boldsymbol{K} u+F_{c}^{D}+F_{c}^{E}=-M \ddot{u}_{g}
$$

Where, $\boldsymbol{M}, \boldsymbol{C}$ and $\boldsymbol{K}$ are respectively the quality matrix, damping matrix, and rigidity matrix; $\iota=[1,1]^{T}, F_{c}^{D}=C_{k} \dot{u}$, and $F_{c}^{E}=K_{k} u-k_{k} g_{p} l$ are respectively the contact force generated by the damper and spring in Kelvin model, with $\boldsymbol{C}_{k}=c_{k}\left[\begin{array}{cc}1 & -1 \\ -1 & 1\end{array}\right], \boldsymbol{K}_{k}=k_{k}\left[\begin{array}{cc}1 & -1 \\ -1 & 1\end{array}\right]$, and $l=[1,-1]^{T} . c_{k}$ and $k_{k}$ are respectively the damping coefficient and rigidity coefficient of Kelvin model.

Without regard to collision, for most general SSH method, the following balance equation is adopted:

$$
a_{m 1} \boldsymbol{M} \ddot{u}_{t+\Delta t}+a_{c 1} \boldsymbol{C} \dot{u}_{t+\Delta t}+a_{k 1} \boldsymbol{K} u_{t+\Delta t}+a_{m} \boldsymbol{M} \ddot{u}_{t}+a_{c} \boldsymbol{C} \dot{u}_{t}+a_{k} \boldsymbol{K} u_{t}=-a_{f 1} \boldsymbol{M} i \ddot{u}_{g}(t+\Delta t)+a_{f} \boldsymbol{M} \ddot{u}{ }_{g}(t)
$$

Displacement and velocity are expressed as follows:

$$
u_{t+\Delta t}=u_{t}+\Delta t \dot{u}_{t}+\beta \Delta t^{2} \ddot{u}_{t}+\beta_{1} \Delta t^{2} \ddot{u}_{t+\Delta t}, \quad \dot{u}_{t+\Delta t}=\dot{u}_{t}+\gamma \Delta t \ddot{u}_{t}+\gamma_{1} \Delta t \ddot{u}_{t+\Delta t}
$$

Wherein, $a_{m 1}, a_{m}, a_{c 1}, a_{c}, a_{k 1}, a_{k}, a_{f 1}, a_{f}, b_{m 1}, b_{m}, \gamma_{m 1}$, and $\gamma_{m}$ are all parameters.

The displacement expression in Equation (5) is used to get:

$$
\ddot{u}_{t+\Delta t}=\frac{1}{\beta_{1} \Delta t^{2}}\left(u_{t+\Delta t}-u_{t}\right)-\frac{1}{\beta_{1} \Delta t} \dot{u}_{t}-\frac{\beta}{\beta_{1}} \ddot{u}_{t}
$$

Substitute Equation (6) into Equation (5) of the velocity expression, so

$$
\dot{u}_{t+\Delta t}=\frac{\gamma_{1}}{\beta_{1} \Delta t}\left(u_{t+\Delta t}-u_{t}\right)+\left(1-\frac{\gamma_{1}}{\beta_{1}}\right) \dot{u}_{t}+\left(\gamma-\frac{\beta \gamma_{1}}{\beta_{1}}\right) \Delta t \ddot{u}_{t}
$$

Substitute Equation (6) and Equation (7) into Equation (4), so

$$
\overline{\boldsymbol{K}} u_{t+\Delta t}=\overline{\boldsymbol{P}}
$$

Where, $\overline{\boldsymbol{K}}=a_{k 1} \boldsymbol{K}+\frac{a_{m 1}}{\beta_{1} \Delta t^{2}} \boldsymbol{M}+\frac{a_{c 1} \gamma_{1}}{\beta_{1} \Delta t} \boldsymbol{C}$,

$$
\begin{aligned}
\overline{\boldsymbol{P}}=-a_{f 1} \boldsymbol{M} i \ddot{u}_{g}(t & +\Delta t)-a_{f} \boldsymbol{M} i \ddot{u}_{g}(t)+\boldsymbol{M}\left[\frac{a_{m 1}}{\beta_{1} \Delta t^{2}} u_{t}+\frac{a_{m 1}}{\beta_{1} \Delta t} \dot{u}_{t}+\left(\frac{a_{m 1} \beta}{\beta_{1}}-a_{m}\right) \ddot{u}_{t}\right] \\
& +\boldsymbol{C}\left[-\frac{a_{c 1} \gamma}{\beta_{1} \Delta t} u_{t}-a_{c 1}\left(1-\frac{\gamma_{1}}{\beta_{1}}\right) \dot{u}_{t}-\left(a_{c}-a_{c 1} \gamma+\frac{a_{c 1} \beta \gamma_{1}}{\beta_{1}}\right) \Delta t \ddot{u}_{t}\right]-a_{k} \boldsymbol{K} u_{t}
\end{aligned}
$$

As recommended by J.T. Chung (Chung, \& Hulbert, 1994, the parameters are defined as follows: 


$$
\begin{gathered}
a_{m 1}=1, a_{m}=-1 / 2, \gamma=-1 / 2, \gamma_{1}=\frac{3}{2}, \beta=\gamma=-\frac{1}{2}, \beta_{1}=\gamma+\gamma_{1}=1, a_{c}=-\frac{2 \beta+\beta_{1}}{4 \beta_{1}^{2}}=0, \\
a_{c 1}=\frac{2 \beta+3 \beta_{1}}{4 \beta_{1}^{2}}=\frac{1}{2}, a_{k}=0, a_{k 1}=\frac{1}{2 \beta_{1}}=\frac{1}{2}, a_{f 1}=a_{k 1}=\frac{1}{2}, a_{f}=a_{k}=0 。
\end{gathered}
$$

Substitute the above parameters into the expression of $\overline{\boldsymbol{K}}$ and $\overline{\boldsymbol{P}}$, and simplify to:

$\overline{\boldsymbol{K}}=\frac{1}{2} \boldsymbol{K}+\frac{1}{\Delta t^{2}} \boldsymbol{M}+\frac{3}{4 \Delta t} \boldsymbol{C} \quad, \quad \overline{\boldsymbol{P}}=-\frac{1}{2} M \ddot{u}_{g}(t+\Delta t)+\boldsymbol{M}\left(\frac{1}{\Delta t^{2}} u_{t}+\frac{1}{\Delta t} \ddot{u}_{t}\right)+C\left(\frac{3}{4 \Delta t} \boldsymbol{u}_{t}+\frac{1}{4} \dot{u}_{t}-\frac{\Delta t}{8} \ddot{\boldsymbol{u}}_{t}\right)$

After $u_{t+\Delta t}$ is figured out, the value $\dot{u}_{t+\Delta t}$ can also come out:

$$
\dot{u}_{t+\Delta t}=\frac{3}{2 \Delta t}\left(u_{t+\Delta t}-u_{t}\right)-\frac{1}{2} \dot{u}_{t}+\frac{\Delta t}{4} \ddot{u}_{t}
$$

Considering collision, add the collision term at the left of Equation (4), with the equilibrium equation as follows:

$a_{m 1} M \ddot{u}_{t+\Delta t}+a_{c 1} C \dot{u}_{t+\Delta t}+a_{k 1} K u_{t+\Delta t}+a_{m} M \ddot{u}_{t}+a_{c} C \dot{u}_{t}+a_{k} K u_{t}+a_{F c 1} F_{c}(t+\Delta t)+a_{F c} F_{c}(t)=-a_{f 1} M v \ddot{u}_{g}(t+\Delta t)+a_{f} M i \ddot{u}_{g}(t)$

The parameters shall take the same values as in the case without considering the collision force, and let

$$
\begin{aligned}
& a_{F C 1}=a_{k 1}=1 / 2, a_{F c}=a_{k}=0, \text { so: } \\
& \overline{\boldsymbol{K}}=a_{0} \boldsymbol{K}+a_{1} \boldsymbol{M}+a_{2} \boldsymbol{C} \text { without collision or } \overline{\boldsymbol{K}}=a_{0}\left(\boldsymbol{K}+\boldsymbol{K}_{k}\right)+a_{1} \boldsymbol{M}+a_{2}\left(\boldsymbol{C}+\boldsymbol{C}_{k}\right) \text { with collision } \\
& \overline{\boldsymbol{P}}\left\{\begin{array}{l}
=-\frac{1}{2} \boldsymbol{M} i \ddot{u}_{g}(t+\Delta t)+\boldsymbol{M}\left(a_{1} u_{t}+a_{3} \dot{u}_{t}\right)+\boldsymbol{C}\left(a_{2} u_{t}+a_{4} \dot{u}_{t}+a_{5} \ddot{u}_{t}\right) \quad \text { without collision } \\
=-\frac{1}{2} \boldsymbol{M} i \ddot{u}_{g}(t+\Delta t) \pm \frac{1}{2} k_{k} g_{p} l+\boldsymbol{M}\left(a_{1} u_{t}+a_{3} \dot{u}_{t}\right)+\left(\boldsymbol{C}+\boldsymbol{C}_{k}\right)\left(a_{2} u_{t}+a_{4} \dot{u}_{t}+a_{5} \ddot{u}_{t}\right) \quad \text { with collision }
\end{array}\right.
\end{aligned}
$$

After $u_{t+\Delta t}$ is figured out, $\ddot{u}_{t+\Delta t}$, and $\dot{u}_{t+\Delta t}$ can also come out:

$$
\ddot{u}_{t+\Delta t}=a_{1}\left(u_{t+\Delta t}-u_{t}\right)-a_{2} \dot{u}_{t}+a_{0} \ddot{u}_{t}, \dot{u}_{t+\Delta t}=\dot{u}_{t}+a_{6} \ddot{u}_{t}+a_{7} \ddot{u}_{t+\Delta t}
$$

Where: $a_{0}=\frac{1}{2}, a_{1}=\frac{1}{\Delta t^{2}}, a_{2}=\frac{3}{4 \Delta t}, a_{3}=\frac{1}{\Delta t}, a_{4}=\frac{1}{4}, a_{5}=-\frac{\Delta t}{8}, a_{6}=4 a_{5}$, and $a_{7}=2 a_{2}$ 


\section{Verification of collision numerical algorithm}

Since there is lack of related test materials regarding collision of the beam and transverse anti-shock block, and many tests have been performed for collision between adjacent structures such as adjacent buildings in virtue of simulation by two towers. Correctness of the program is verified in an indirect way; that is to say, the above method for calculation of the beam-block collision is modified by dropping the mutual action of the rubber bearing between the beam and the block, in order to solve this kind of collision problem.

\section{Steel-steel collision test}

Chau et al. (2003) once performed the collision test by two steel towers on the vibration table of $3 \mathrm{~m} \times 3 \mathrm{~m}$ in The Hong Kong Polytechnic University, with the process as follows: Two adjacent steel frames in different sizes are built, with one steel plate welded on each steel frame, and one steel ball of $50 \mathrm{~mm}$ in diameter welded on the left tower. Initial clearance of the contact body is $11 \mathrm{~mm}$. the dynamic property of both left and right steel towers are respectively $m_{1}=204.0 \mathrm{~kg}, f_{1}=2.31 \mathrm{~Hz}, \zeta_{1}=0.014 ; m_{2}=146.5 \mathrm{~kg}, f_{2}=2.90 \mathrm{~Hz}, \zeta_{2}=0.016$; under the action of El Centro wave SE component in 1940, the velocity time-history curve of Tower 1 is figured out through the shaking table test, as shown in Figure 3. The author also gives the numerical calculation result, as shown in Figure 4.

\begin{tabular}{ccccc}
\multicolumn{5}{c}{ Table1. Parameters for steel-steel collision. Physical properties of low carbon steel } \\
\hline \multirow{2}{*}{ Specimen } & $\begin{array}{c}\text { Modulus of } \\
\text { elasticity } E(\mathrm{MPa})\end{array}$ & $\begin{array}{c}\text { Poisson } \\
\text { ratio } \mu\end{array}$ & $\begin{array}{c}\text { Density } \\
\rho\left(\mathrm{kg} / \mathrm{m}^{3}\right)\end{array}$ & Mass $m(\mathrm{~kg})$ \\
\hline 1 & $21.2 \times 10^{4}$ & 0.31 & 7850 & 204.0 \\
2 & $21.2 \times 10^{4}$ & 0.31 & 7850 & 146.5 \\
\hline
\end{tabular}

Figure 3. Velocity test results of Tower 1 (Source: Chau et al., 2003).

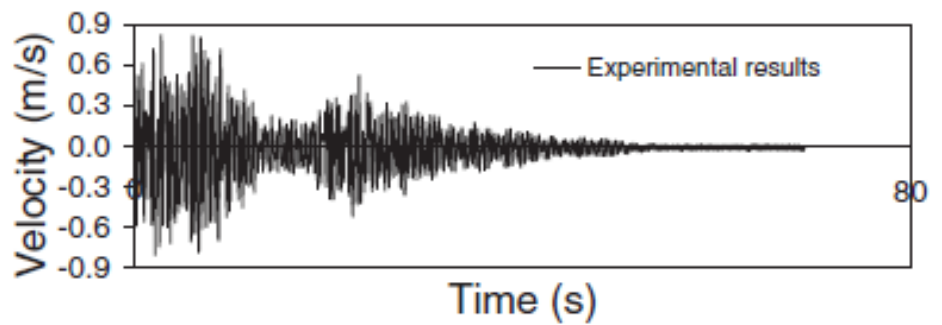

Figure 4. Velocity calculation results given by Ref.(Chau et al. (2003) of Tower 1.

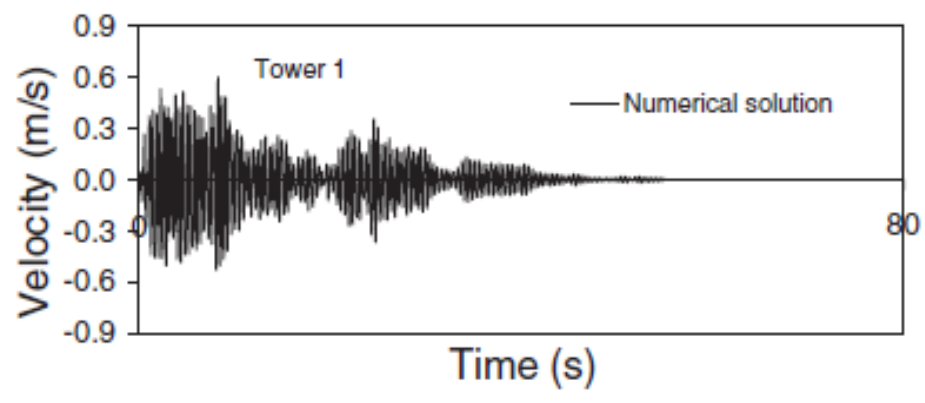


The velocity time-history and collision force time-history got from the modified calculation procedure are shown in Figure 5 and 6 . It can be seen that however there is some deviation between the prediction of the velocity time-history and the test record in some time points, the results are consistent on the whole. The collision times of 44 calculated by the numerical calculation is only $8.3 \%$ less than the number of 48 collisions recorded by the test.

Figure 5. Velocity calculation results of Tower 1. (Self-Elaboration).

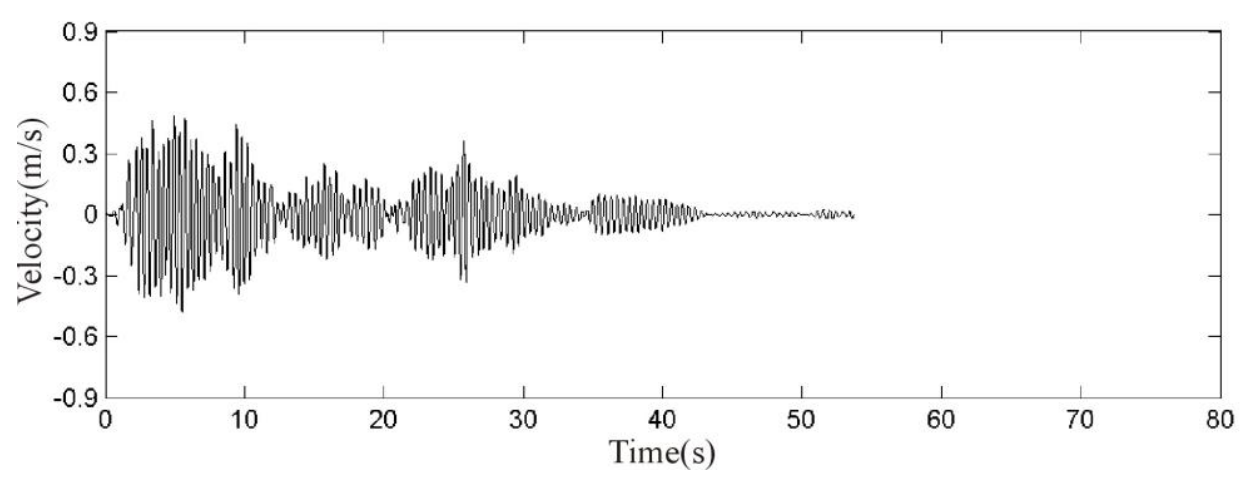

Figure 6. Impact force calculation results. (Self-Elaboration).

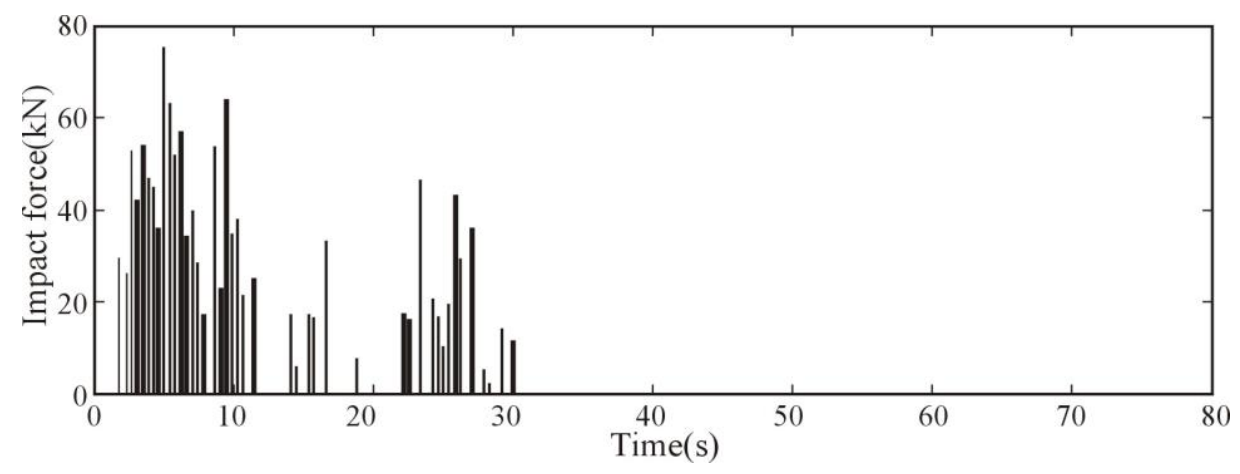

\section{Concrete-concrete collision test}

Jankowski (2009) also performed the similar collision test in Gdańsk University of Technology to study the collision reaction of different materials. The dynamic properties of both left and right steel towers are respectively: $m_{1}=10.004$ $\mathrm{kg}, f_{1}=2.59 \mathrm{~Hz}, \zeta_{1}=0.004 ; m_{2}=19.226 \mathrm{~kg}, f_{2}=2.99 \mathrm{~Hz}, \zeta_{2}=0.01$. Jankowski performed the shaking table test for the collision object made of steel, concrete, timber, and ceramic. El Centro accelerated time-history in 1940 is adopted for the earthquake wave, studied the reaction of both towers in each material in the case of different initial gaps, and gave the displacement time-history of both towers when the initial clearance is $40 \mathrm{~mm}$, where the displacement time-history for concrete material is shown in Figure 7. Where, (a) is the displacement time-history in case of collision, (b) is the displacement time-history for free vibration. It is seen from Figure 7 that collision clearly changed the seismic reaction of the structure.

Table 2. Parameters for concrete-concrete collision. (Self-Elaboration).

\begin{tabular}{ccccc}
\hline Specimen & $\begin{array}{c}\text { Modulus of elasticity } \\
\mathrm{E}(\mathrm{MPa})\end{array}$ & $\begin{array}{c}\text { Poisson } \\
\text { ratio } \mu\end{array}$ & $\begin{array}{c}\text { Density } \\
\rho\left(\mathrm{kg} / \mathrm{m}^{3}\right)\end{array}$ & Mass $\mathrm{m}(\mathrm{kg})$ \\
\hline 1 & $3.25 \times 10^{4}$ & 0.18 & 2500 & 10.004 \\
2 & $3.25 \times 10^{4}$ & 0.18 & 2500 & 43.5 \\
\hline
\end{tabular}


Figure 7. Displacement of concrete-concrete impact test: (a) impact; (b) vibration. Source: Jankowski (2009).
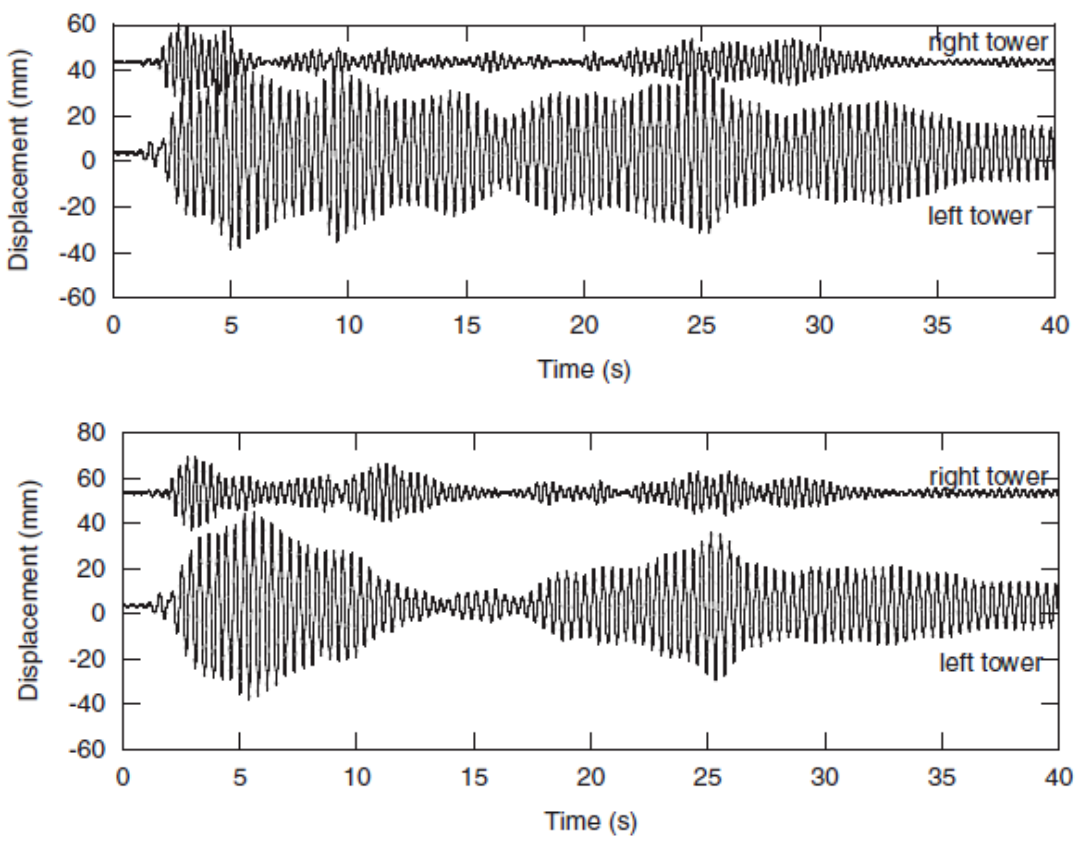

As mentioned above for steel-steel collision, the modified calculation program can be used to get the time-history of displacement for concrete-concrete collision, as shown in Figure 8 (a); the time-history of displacement when there is no collision between towers is figured out, as shown in Figure 8 (b). It is found that the calculated results and the measured results are consistent on the whole, which means the calculation program developed in the paper is correct and feasible.

Figure 8. Displacement calculation results of concrete-concrete impact: (a) impact; (b) vibration. (Self-Elaboration).
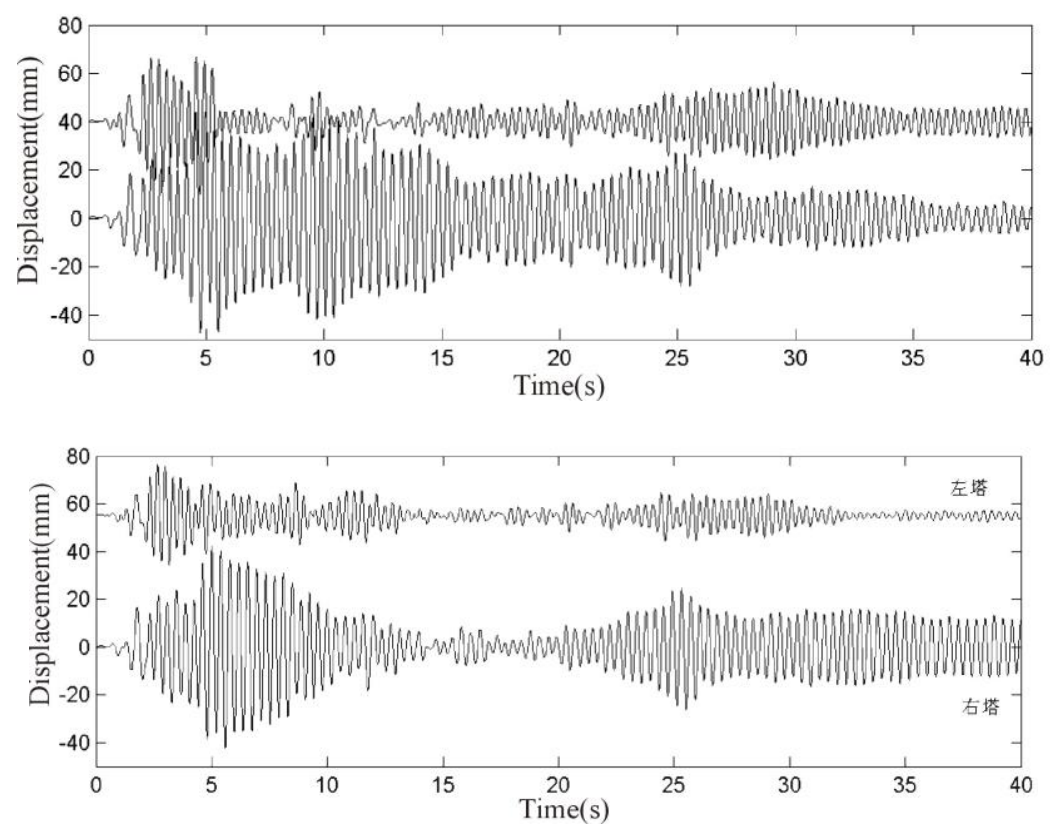

\section{Application example}

The arrangement plan of the beam, bent cap, pier, and block of certain bridge in transverse direction is shown in Figure 9. C50 concrete is used for the beam, while C40 concrete for others. The plate-type rubber base is used for the support, with the model number of $\$ 600 \times 90 \mathrm{~mm}$, with 2 supports arranged for each bent cap in transverse bridge 
direction. The lateral rigidity of the pier is $k_{1}=3.287 \times 10^{7} \mathrm{~N} / \mathrm{m}$. To calculate the fundamental frequency of the pier containing the bent cap, the mass of the lower structure is defined as the mass of the bent cap plus half the mass of the pier, i.e. $m_{1}=33205 \mathrm{~kg}$. The beam part is defined as the mass of one span of girder, $m_{2}=190000 \mathrm{~kg}$. The Hertz contact rigidity is $2.2818 \times 10^{10} \mathrm{~N} / \mathrm{m}^{3 / 2}$, while Kelvin contact rigidity is the equivalent Kelvin model rigidity put forward in Reference (Fuqing, 2007). The initial clearance is $g_{p}=0.05 \mathrm{~cm}$.

Figure 9. Bridge schematic plan (unit: cm). Source: Fuqing (2007).

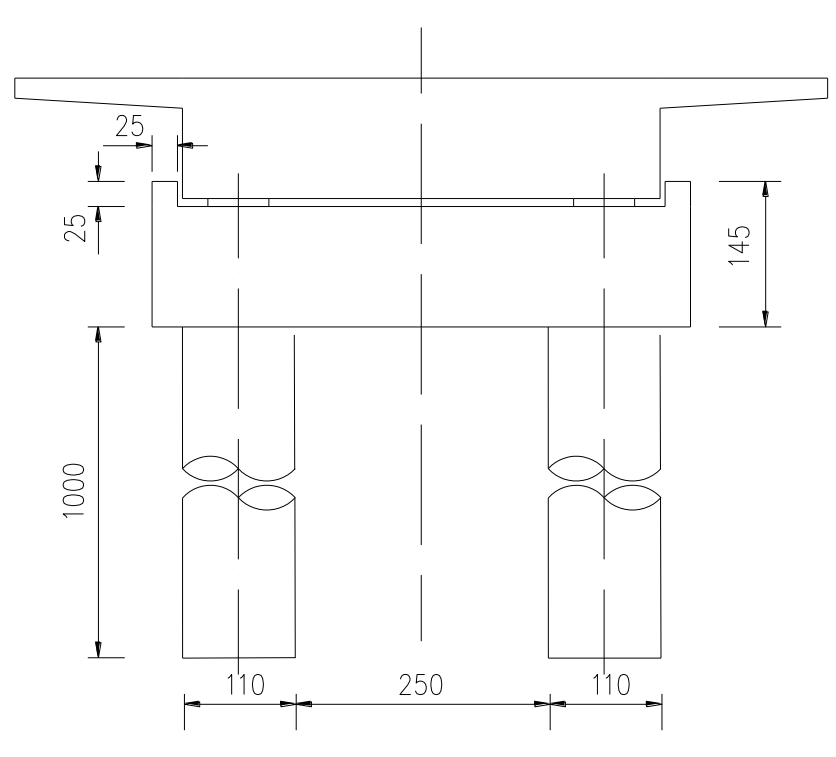

The experimental result of the plate-type rubber base indicates that the hysteretic curve is long and narrow, which can be assumed approximately as line (Fan et al., 2001). The horizontal restrain of the support to the beam is simulated by the linear spring. The equivalent shear rigidity of the plate-type rubber support is $K=G A / \sum t$, where, $\mathrm{G}$ is the support shear modulus, taken as $1.0 \mathrm{MPa}$. A is the shear area of the support, $\Sigma t$ is the total thickness of the rubber piece. In the example, $\sum t=0.065 \mathrm{~m}$, so $K=4.348 \times 10^{6} \mathrm{~N} / \mathrm{m}$, and as a result, the lateral rigidity of the support is $k_{2}=8.696 \times 10^{6} \mathrm{~N} / \mathrm{m}$.

Two earthquake valves are selected such as Ninghe Tianjin north-south wave (hereinafter referred to as Tianjin wave) and Beijing Hotel measuring point north-south wave (hereinafter referred to as Beijing wave), with the peak valve adjusted to $0.3 \mathrm{~g}$ and $8 \mathrm{~s}$ is taken for each case. Interpolation is made to two waves, with the step length of $0.0002 \mathrm{~s}$. the calculation results are respectively shown in Figures 10 and 11. 
Figure 10. Calculation results under Tianjin earthquake: (a) displacement no impact; (b) displacement considering of impact; (c) impact force. (Self-Elaboration).
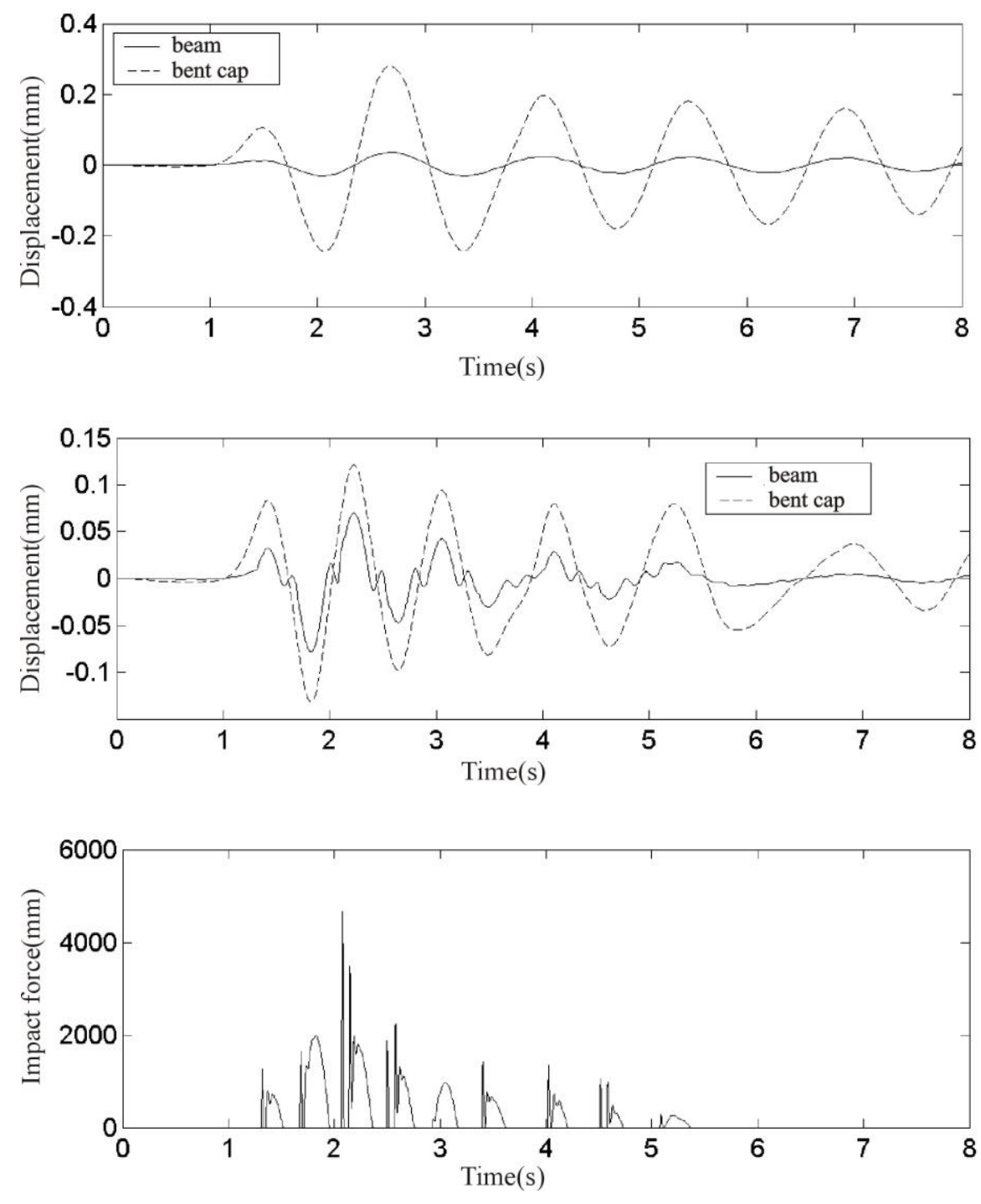

Figure 11. Calculation results under Beijing earthquake: (a) displacement no impact; (b) displacement considering of impact; (c) impact force. (Self-Elaboration).
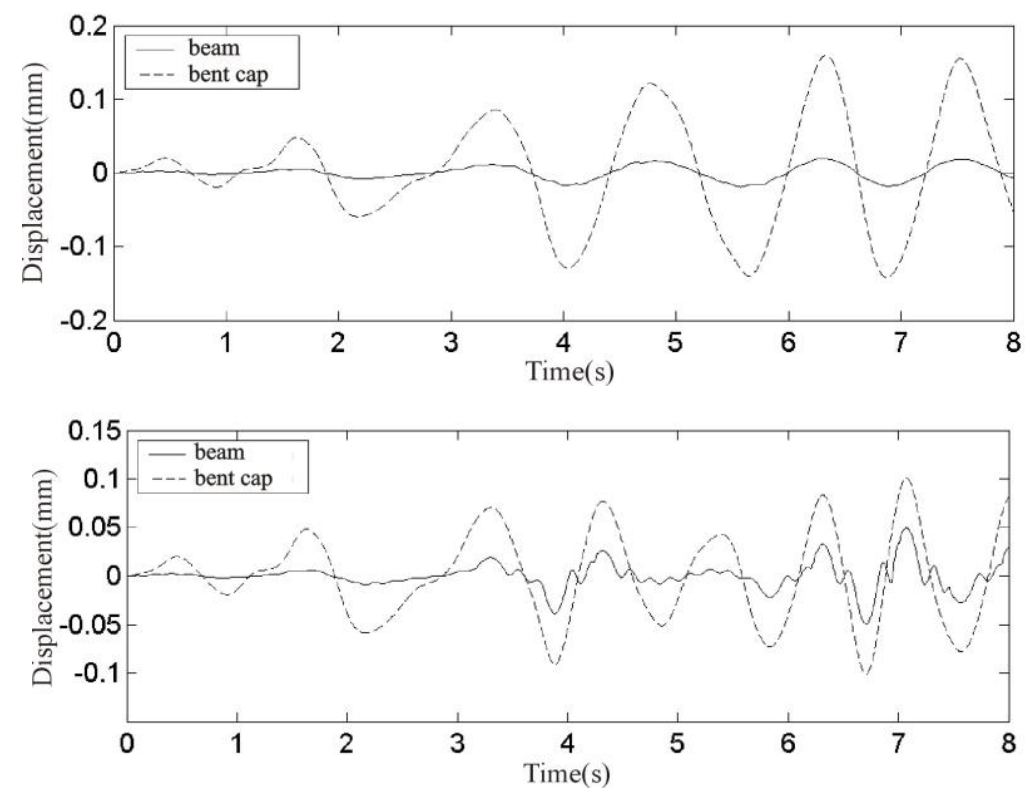


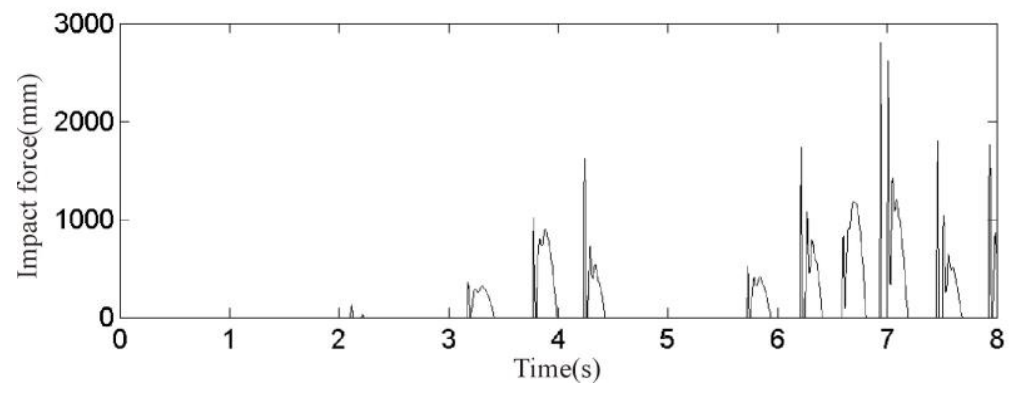

The conclusions drawn from the comparison between the time-history of displacement before and after the collision reveal that the collision exerts pronounced impact on seismic reaction of the structure.

Kelvin contact unit model and SSH method are used to deduce the calculation method and procedures of the seismic response in transverse direction of bridge considering the beam-block collision effect, which is a transition of collision effects from qualitative research to quantitative research. The following conclusions can be drawn from the analysis as mentioned above:

(1) Compared to the steel-steel collision test, the calculated time-history of velocity is consistent in the whole, which is detailed as the collision times of 44 calculated by the numerical calculation is only $8.3 \%$ less than the number of 48 collisions recorded by the field test.

(2) The calculated results involved in this study are in agreement with the measured results captured from the concrete-concrete collision test, which means that the calculation program developed in the paper is correct and feasible.

(3) The collision exerts so pronounced impact on seismic reaction of the structure that it is of paramount importance to pay more attention to impacts of collisions during design of the lower structure.

References

Azadeh B., Megally, Ashford S., Restrepo J. I. (2007). Seismic response of sacrificial exterior shear keys in bridge abutments (A). Final Report Submitted to the California Department of Transportation (Caltrans). University of California, Department of Structural Engineering, Structural Systems Research Project. San Diego.

Chung, J. \& Hulbert, G.M. (1994). A family of single-step Houbolt time integration algorithms for structural dynamics. Comput. Methods Appl. Mech. Engrg., 118(1), 1-11.

Fan, L., Hu, S., \& Ye, A. (2001). Seismic design for long span bridges. Beijing: China Communications Press.

Goel, R.K. \& Chopra, A.K. (2008). Role of Shear Keys in Seismic Behavior of Bridges Crossing Fault-Rupture Zones[J]. Journal of Bridge Engineering, 13(4), 398-408.

Hilber, H. M. \& Hughes, T. J. R. (1976). Collocation, dissipation and 'overshoot' for time integration schemes in structural dynamics[J]. Earthquake Engng Struct. Dyn., 6(1), 99-117.

Houbolt, J.C. (1950). A recurrence matrix solution for the dynamic response of elastic aircraft[J]. Journal of the Aeronautical Science, 17(9), $540-550$.

Hulbert, G.M. \& Chung J. (1996). Explicit time integration algorithms for structural dynamics with optimal numerical dissipation. Comput. Methods Appl. Mech. Engrg., 137(2), 175-188.

Chau, K.T., Wei, X.X., Guo, X. \& Shen, C.Y. (2003). Experimental and theoretical simulations of seismic poundings between two adjacent structures[J]. Earthquake Engng Struct. Dyn., 32, 537-554. 
Fuqing, Y. (2007). Pounding responses and control of isolated elevated bridges during earthquake [D] . Tianjin: Tianjin University. (in Chinese).

Jankowski, R. (2009). Experimental study on earthquake-induced pounding between structural elements made of different building materials. Earthquake Engng Struct. Dyn., 39, 343-354.

Li, Q., Zhao, S., et al. (2008). Analysis on Seismic Damages of Projects Subjected to Wenchuan Earthquake. Chengdu: Southwest Jiaotong University Press. (in Chinese).

Maleki, S.P.E. (2004). Effect of Side Retainers on Seismic Response of Bridges with Elastomeric Bearings. Journal of Bridge Engineering, 9(1), 95-100.

Megally, S.H., Silva, P.F. \& Seible, F. (2001). Seismic response of sacrificial shear keys in bridge abutments(A). Final Report Submitted to Caltrans University of California, Department of Structural Engineering, Structural Systems Research Project. San Diego.

Petros, K., Panayiotis, C., Loizos, P., et al. (2007). Response of seismically isolated buildings considering poundings[J]. Earthquake Engng Struct. Dyn., 36(3):1605-1622.

Wand, D., Guo, X., Sun, Z., et al. (2009). Damage to highway bridges during Wenchuan earthquake[J]. Journal of Earthquake Engineering and Engineering Vibration, 29(3), 84-94. (in Chinese). 